\title{
Meis2 is essential for cranial and cardiac neural crest development
}

\author{
Ondrej Machon ${ }^{1 *}$, Jan Masek', Olga Machonova', Stefan Krauss² and Zbynek Kozmik
}

\begin{abstract}
Background: TALE-class homeodomain transcription factors Meis and Pbx play important roles in formation of the embryonic brain, eye, heart, cartilage or hematopoiesis. Loss-of-function studies of Pbx1, 2 and 3 and Meis 1 documented specific functions in embryogenesis, however, functional studies of Meis 2 in mouse are still missing. We have generated a conditional allele of Meis 2 in mice and shown that systemic inactivation of the Meis 2 gene results in lethality by the embryonic day 14 that is accompanied with hemorrhaging.

Results: We show that neural crest cells express Meis2 and Meis2-defficient embryos display defects in tissues that are derived from the neural crest, such as an abnormal heart outflow tract with the persistent truncus arteriosus and abnormal cranial nerves. The importance of Meis2 for neural crest cells is further confirmed by means of conditional inactivation of Meis2 using crest-specific AP2a-IRES-Cre mouse. Conditional mutants display perturbed development of the craniofacial skeleton with severe anomalies in cranial bones and cartilages, heart and cranial nerve abnormalities.
\end{abstract}

Conclusions: Meis2-null mice are embryonic lethal. Our results reveal a critical role of Meis2 during cranial and cardiac neural crest cells development in mouse.

Keywords: Meis2, Neural crest, Persistent truncus arteriosus, Craniofacial skeleton, Cranial nerves

\section{Background}

Neural crest cells (NCC) represent a multi-potent embryonic cell population that generates a very diverse range of cell types including cranial nerves, neurons and glia of the peripheral nervous system, enteric neurons, melanocytes, cranial bones and cartilages [1,2]. The first NCC appear at the neurula stage in the neural plate border region. As the neural tube closes in mouse, NCC delaminate from the regions of neural plate border and ectomesenchyme after epithelial-to-mesenchymal transition (EMT) and migrate to various developing organs. The very broad differentiation potential of NCC provides a complex model of cell type specification and migration and the gene regulatory network determining the spatiotemporal control of NCC diversification has been extensively studied. For instance, the NCC population is specified by the set of transcription factors Sox9, Sox10, FoxD3, Snai2 together with Msx1, Pax3/7 or Zic1 in the

\footnotetext{
* Correspondence: machon@img.cas.cz

${ }^{1}$ Institute of Molecular Genetics, The Czech Academy of Sciences, 14200

Praha, Czech Republic

Full list of author information is available at the end of the article
}

neural plate border [3]. These effector genes are regulated by coordinated action of signaling pathways such as Wnt, Bmp and Fgf from the adjacent paraxial mesoderm and non-neural ectoderm [2, 4]. The differentiation potential of NCC is spatially determined by their position along the rostrocaudal axis. In a simplified view, cranial NCC coming from mesencephalic and rhombencephalic regions generate head bones, cartilages, cranial nerves and selected connective tissues [5, 6]. Vagal NCC from the area of somites 1-7 are destined to the enteric nervous system. Cardiac NCC (somites 1-4) are involved in septation of the cardiac outflow tract [7] and trunk NCC form sensory and sympathetic ganglia. The current debate, however, favors the scenario proposing that originally multi-potent NCC stem cells are exposed to different environmental cues along the rostrocaudal axis that spatiotemporally restrict their differentiation potential $[1,8]$.

Meis proteins are transcription factors that are orthologous to the Drosophila homothorax (Hth) protein. They contain a TALE (three-amino-acid loop extension) sub-class of the homeodomain that binds to DNA. In 
humans and mice, three homologues Meis1, Meis2 and Meis3 have been identified [9] and it has been shown that they directly bind to Pbx proteins [10-12]. The Meis/Pbx protein complex binds to DNA through respective Meis- and Pbx-consensus binding sites thereby regulating transcription. The Meis/Pbx complex plays important roles during development of several organs including limbs [13, 14], heart [15, 16], lens [17], pancreas [18] and hindbrain [19-22]. Hox genes are among the target genes of Meis-Pbx control via modulation of histone acetylation indicating recruitment of Hox proteins as cofactors of Meis-Pbx complex [23, 24].

Mice lacking Meis1 display liver hypoplasia, hemorrhage, impaired erythropoiesis and eye defects, and die by the embryonic day (E) $14.5[25,26]$. Although a substantial amount of data have been reported on the role of Meis1 in organogenesis, hematopoiesis and leukemia induction, the function of the other homologs, Meis 2 and Meis3, is much less clear. Chicken Meis2 has a specific role in determining cell fate in the midbrainhindbrain boundary by controlling the expression of Otx2 [22] and it also affects proliferation of retinal progenitor cells [27]. Several recent reports in various model systems indicated that Meis2 may play a role in neural crest cells. Meis2 was identified as one of the key transcription factors in the gene regulatory network driving differentiation of human embryonic stem cells towards cardiovascular cell types, and this was further confirmed by knock-down experiments in zebrafish [16]. Morpholino-based screens in zebrafish revealed the importance of Meis1 and Meis2 factors during craniofacial development [28]. Moreover, gene expression analysis of EMT in endocardial cushions identified Meis2 among enriched genes [29]. In this context it is very interesting that some human disorders displaying cleft palate and heart developmental defects have been linked to mutations in the Meis2 locus [30-33]. Nonetheless, a clear picture of the Meis2 function based on a genetic mouse model is still missing.

In the present study, we examined the role of Meis2 during embryogenesis by generating conditional knockout mice. We studied morphological defects after either zygotic inactivation of the Meis 2 allele or NCC-specific conditional knock-out using AP2 $\alpha$-IRES-Cre. We conclude that hemorrhaging most probably causes embryonic lethality. Further, many embryonic defects in the tissues derived from neural crest in systemic Meis2-nulls were recapitulated upon conditional deletion of Meis 2 in NCC suggesting an indispensable role of Meis2 in NCC.

\section{Results}

Meis2-/- embryos are lethal and display hemorrhaging A conditional mutant allele of the Meis2 gene (Meis2 cKO) was created by inserting LoxP sites in the introns
2 and 6 that flank exons 3 and 6 in the Meis 2 gene (Fig. 1a). To generate mutant mice lacking functional Meis2 in the whole organism, Meis2 cKO were at first crossed with the Hprt1-Cre mice (Jax Mice and Services) that exert a zygotic expression of Cre recombinase facilitating gene excision in all tissues. The first generation mice, which were heterozygous for the Meis2 gene (Meis2+/-), were intercrossed to obtain Meis2-null (Meis2-/-) animals. Animals were genotyped using primers flanking loxP sites as depicted in Fig. 1a. The loss of exons 3-6 in Meis2-/- embryos was tested by PCR (Fig. 1a, left). The absence of Meis 2 protein was verified using Western blot analysis of protein extracts from E12.5 embryos (Fig. 1b, right). Meis2-/- mice displayed embryonic lethality between E13.5-E14.5 and suffered from hemorrhaging (Fig. 1c). The size of mutant embryos was smaller at E14.5 as mutant embryos stopped growing approximately at E13.5 when hemorrhaging became prominent. Although the severity of this phenotype varied among Meis2-/- $(\mathrm{n}=29$ litters, $51 \mathrm{mu}-$ tants), all mutants displayed bleeding and a small liver size (Additional file 1: Figure S1B).

A detailed inspection of internal organs in mutant embryos revealed that the liver was the most impaired organ with a destructed cellular organization in large regions (Additional file 1: Figure S1C-D). These impaired regions contained almost no erythrocytes labelled with Ter119 but many apoptotic cells as shown by TUNEL assay (Additional file 1: Figure S1E-F). Surprisingly, Meis2 was not found to be expressed in the fetal liver while Meis1 was readily detectable (Additional file 1: Figure S1A). Based on this we suggest that the observed cell death in the liver is a consequence of strong hemorrhaging in the whole embryo that leads to anemia and apoptosis primarily in the liver and may be a cause of the embryonic lethality. Having observed anemia in Meis2-/- embryos we further pursued the possibility that Meis2 may influence embryonic hematopoiesis similarly to Meis1 that controls proliferation of hematopoietic stem cells in the fetal liver and is also essential for megakaryocyte viability [25, 26, 34]. We therefore mapped the expression of Meis2 and Meis1 in the area of the aortagonad-mesonephros (AGM), the site of origin of embryonic hematopoietic stem cells. As shown in Additional file 1: Figure S2B, neither Meis2 nor Meis1 were observed in endothelial cells labelled with CD31 but both proteins were abundant in the mesenchyme surrounding the endothelial wall of the dorsal aorta. We further found that circulating hematopoietic progenitors labeled with anti-Runx1 antibody did not express Meis2 (Additional file 1: Figure S2C). Finally, we carried out erythroblast cultures derived from the fetal liver and found no differences in the growth and differentiation of liver erythroid progenitors between Meis2-/- and 


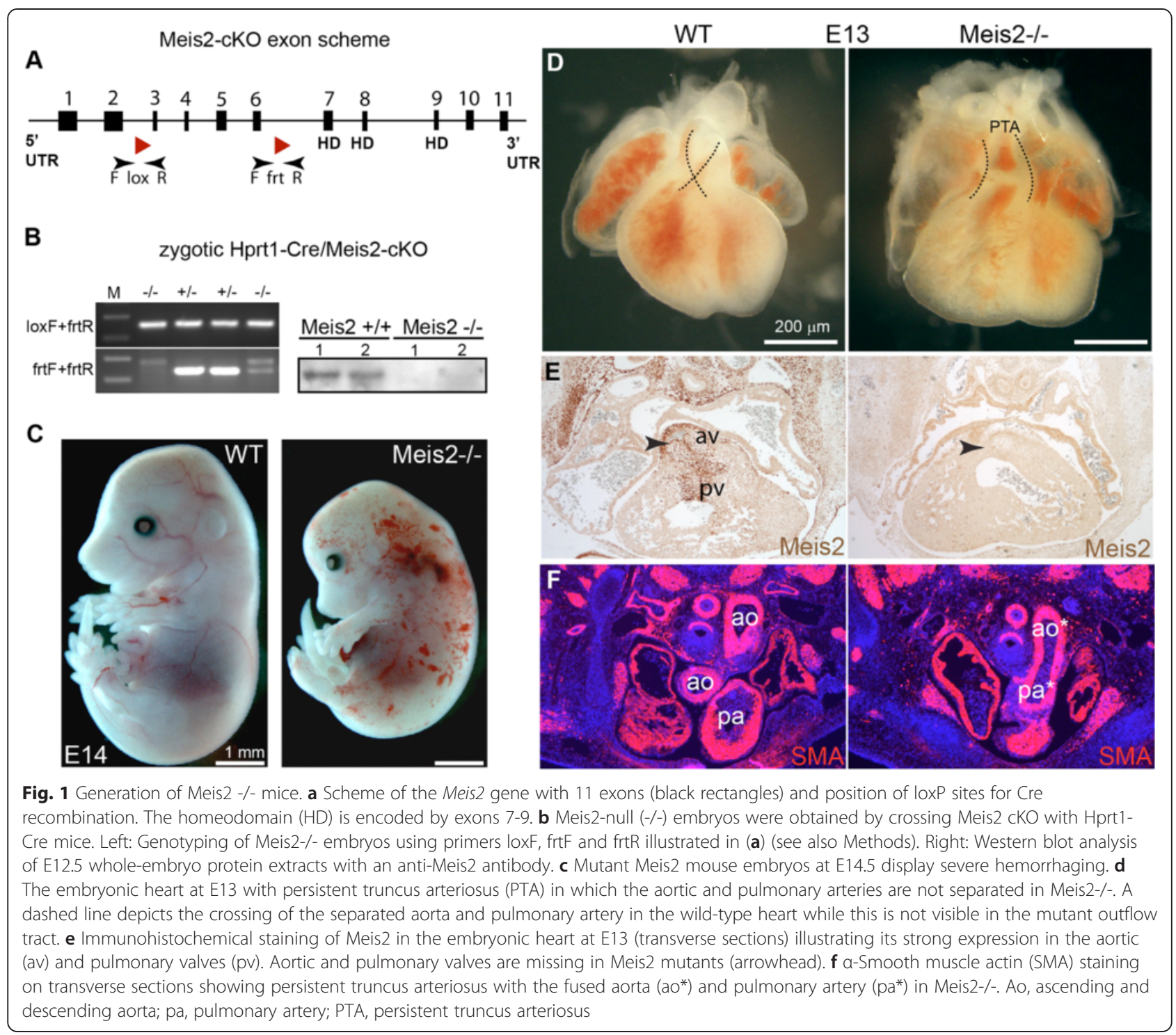

controls (data not shown). As Meis2, in our hands, was not detected in hematopoietic progenitors neither in the AGM nor in the fetal liver, we hypothesize that the anemia in the mutants originates from extensive bleeding or defective circulation rather than defects in hematopoiesis.

\section{The lack of Meis 2 results in fetal heart malformation}

In the heart of Meis2-/- embryos at E12.5, we observed incomplete septation of the outflow tract that normally separates the aorta from the pulmonary artery. This defect is known as persistent truncus arteriosus (PTA) and was observed in all analyzed mutants $(n=8$ litters, 14 mutants) (Fig. 1d). To correlate the observed defects with the expression of Meis2, we carried out immunohistochemistry on sections of embryonic heart at E13 using anti-Meis2 antibody. As shown in Fig. 1e, a remarkably strong presence of Meis2 was observed in the aortic and pulmonary valves. Strikingly, these valves were lost in the Meis2-/- heart (arrowheads). To visualize the PTA in the Meis2-/- outflow tract, we used antibody against $\alpha$-smooth muscle actin (SMA). Stained heart sections confirmed the PTA but SMA appeared normally expressed in the mutant heart (Fig. 1f).

Widespread expression of Meis2 was observed in the developing embryo including the central nervous system, in the upper and lower jaw and in the lumen of the intestinal tract (Fig. 2a). Specifically in the heart, Meis2 protein was detected in the myocardium (arrow) and pericardium (arrowhead) (Fig. 2a') in which Meis2-positive cells also expressed sarcomeric actin (Fig. 2f-f', arrows). Remarkably strong expression of Meis2 was found in the valves (aortic, pulmonary, tricuspid and mitral) as well as in the atrioventricular cushion (Fig. 2b-f'). 


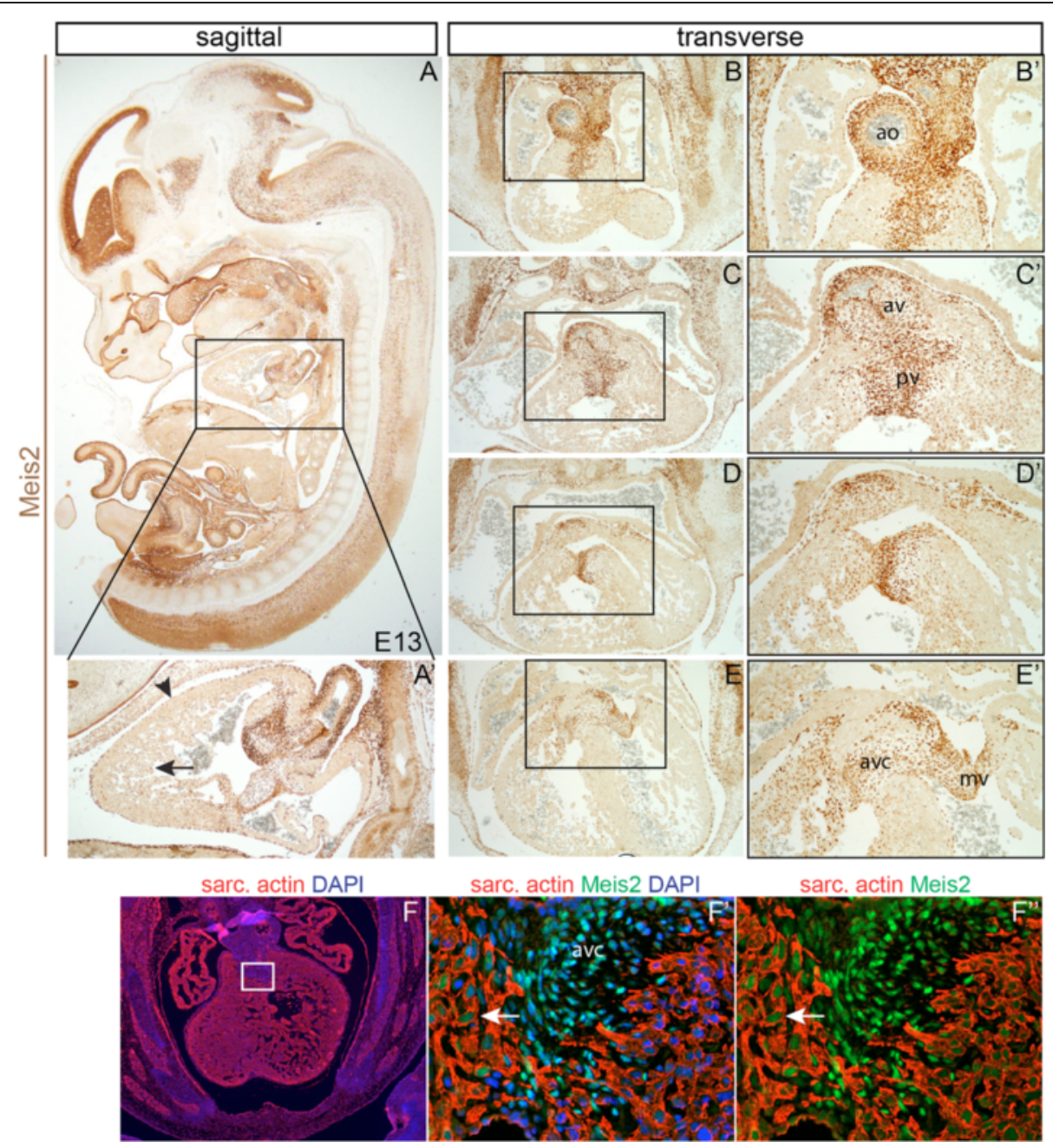

Fig. 2 Mapping of Meis2 expression in the mouse embryo at E13. Meis2 protein is present in many developing tissues including the forebrain, midbrain, hindbrain, spinal cord, myocardium, cardiac cushions, cardiac outflow tract, valves (aortic, pulmonary, tricuspid, mitral). (a) A sagittal section of the whole embryo with a detail of the heart ( $A^{\prime}$ ) documenting Meis2 presence in the myocardium (arrow) and pericardium (arrowhead). (b-e) Transverse sections of the heart at E13 from rostral to caudal with details of the framed areas ( $\mathbf{b}^{\prime}$-e') illustrating strong Meis2

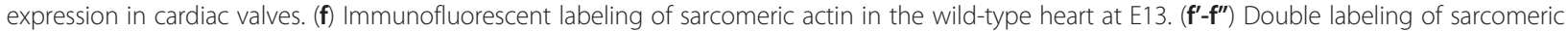
actin (red) and Meis2 (green), a higher magnification view on the framed area in (f) showing Meis2 in the myocardium (arrows) and in the atrioventricular cushion. ao, aorta; av, aortic valve; pv, pulmonary valve; mv, mitral valve; avc, atrioventricular cushion

To document heart defects in Meis2-/- embryos in detail, we performed immunofluorescence on transverse and sagittal sections from embryos at E12.5 using antibodies against Meis2, $\alpha$-smooth muscle actin (SMA) and heart-specific myosin Myl7. Figure 3a-c illustrates that the aortic and pulmonary arteries were not separated (ao*, pa*, pv" in Fig. 3b) and the aortic valve was absent (arrowhead in Fig. 3a). These regions strongly expressed Meis2 in the controls and the signal was lost in the mutants (Fig. 3a). Both the aortico-pulmonary spiral septum and the aortic and pulmonary valves are formed from from cardiac neural crest cells [7] which can be visualized by anti-Sox 9 and anti-Twist1 antibody [35]. In Meis2-/- embryonic hearts, we observed less Sox9- positive cells in the outflow valves. The number of Twist1-positive cells was not significantly changed though its expression level was reduced and the organization of these cells was altered compared to controls (Fig. 3d). Clear morphological defects in the septation of the truncus arteriosus and in the outflow valves (arrowheads) strongly suggest that the defective outflow tract in Meis2 nulls arises from impaired cardiac neural crest cells.

\section{Neural crest cells express high levels of Meis2}

Based on the heart abnormalities of potential neural crest origin, we decided to map the expression of Meis2 at the embryonic stages that are critical for generation and migration of NCC. At E8.5 before the neural tube 


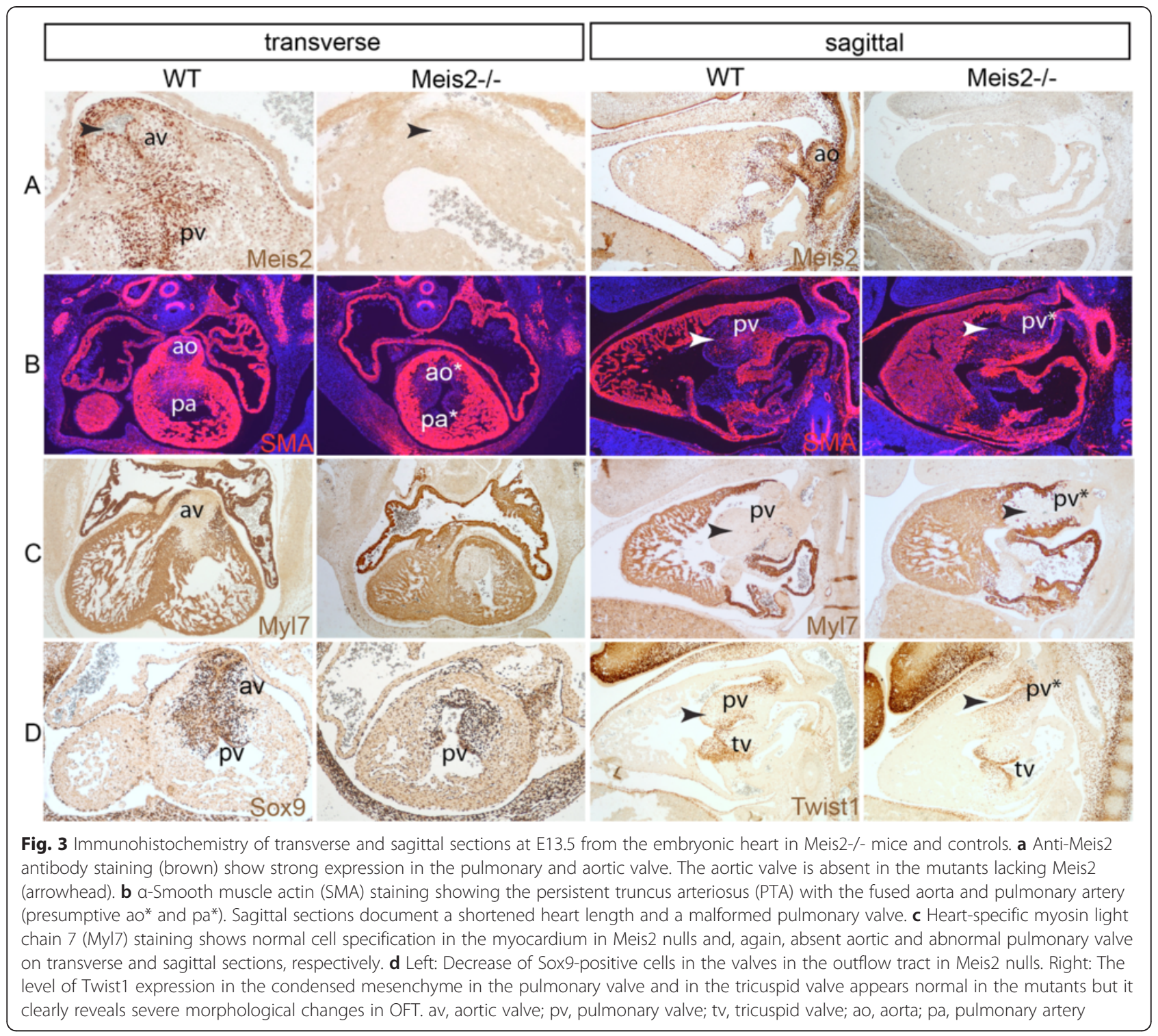

closure, abundant Meis2 expression was noticed in the neural plate that weakened towards the plate border from which the premigratory NCC delaminate (Fig. 4a). At E9.5, the Meis2 protein was found in the neuroepithelium of the hindbrain (Fig. 4b-b") in which the signal became diminished towards the roof plate. Meis2 was also seen in migrating cells in the mesenchyme lateral to the hindbrain and in the pharyngeal arches 1-2 (PA1 and PA2) (Fig. 4b') and in the outflow tract (OFT) (Fig. 4B"). Many of these cells especially in the PA co-express Tfap2, a marker of NCC [36, 37] (Fig. 4c-c" and Additional file 1: Figure S3C-D"). At E10.5, Meis2 protein was detected in the developing tissues that are derived from NCC, such as the trigeminal and facial nerve ganglions, in the the otic vesicle and its surrounding mesenchyme, in the maxillary and mandibular component of the PA1, in the cardiac outflow tract cushion and in the
PA2 (Fig. 4d-d"' and Additional file 1: Figure S3A-B"). The expression pattern revealed by our immunohistochemistry thus corresponds to in situ hybridization of Meis2 mRNA reported by Cecconi and co-workers [38]. Apart from the neuroectoderm, many of Meis2-positive cells displayed a mesenchymal character as revealed by co-staining with the anti-Twist1 antibody (Fig. 2E and Additional file 1: Figure S3E).

\section{Conditional deletion of Meis2 in neural crest cells leads to a defective heart outflow tract}

Because some developmental defects in Meis2 nulls may arise from affected NCC, we aimed to verify this assumption by means of conditional inactivation of Meis2. We employed AP2 $\alpha$-IRES-Cre (AP2 $\alpha$-Cre) transgenic mouse in which Cre recombinase was inserted into the Tfap2 (AP2 $\alpha$ ) gene enabling loxP recombination specifically 

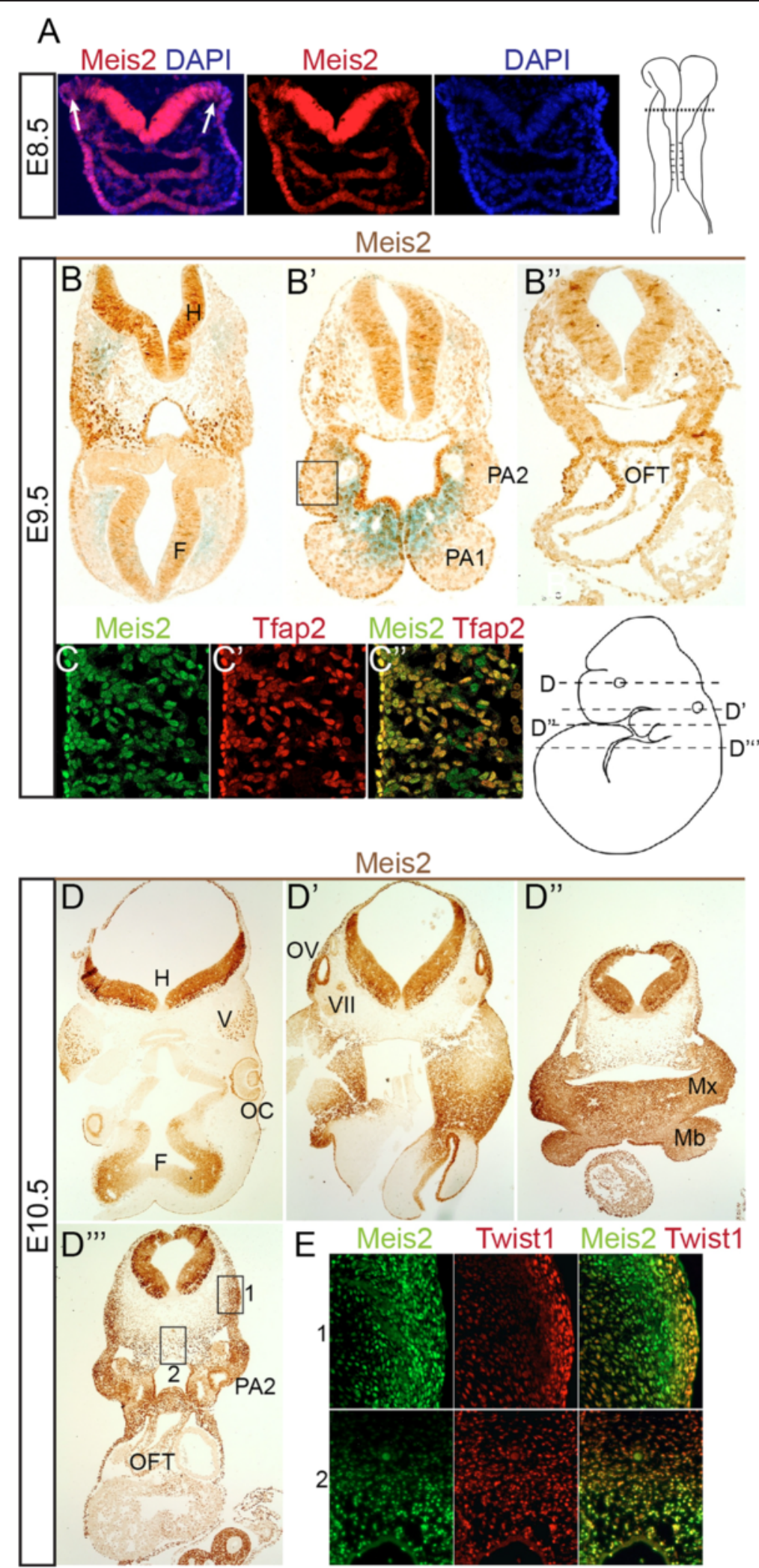

Fig. 4 (See legend on next page.) 
(See figure on previous page.)

Fig. 4 Meis2 is expressed in migrating NCC. (a) Meis2 expression in the neural plate stage at E8.5 becomes weak towards the neural plate border

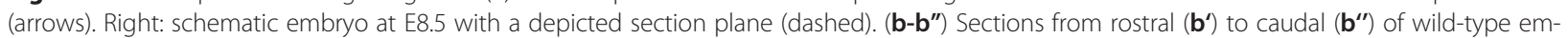
bryos at E9.5 revealing Meis2 in pharyngeal arches (PA), hindbrain (H) and in the cardiac outflow tract (OFT). (c- $\left.\mathbf{c}^{\prime \prime}\right)$ Immunofluorescent doublelabeling of Meis2 (green) and Tfap2 (red) in the region approximately depicted by a black rectangle in $A^{\prime}$. (d-d"') Transverse sections from rostral to caudal at E10.5 with immunostained Meis2. Sections levels correspond to the illustrated cartoon. Meis2 was detected in the hindbrain (H), forebrain (F), optic cup (OC), trigeminal nerve ganglion (V), otic vesicle (OV), facial nerve ganglion (VII), maxillary (Mx) and mandibular (Mb) process of PA1, in PA2 and outflow tract (OFT). (e) Immunofluorescence of Meis2 (green) and Twist1 (red) shows their co-expression in two areas labelled with rectangles in $\mathrm{D}^{\prime \prime \prime}$. Upper panels (1) belong to the lateral zone (1) and lower panels (2) to the midline area (2)

in NCC [39]. Conditional mutants AP2 $\alpha$-Cre/Meis2 cKO survived the critical stage E14, at which systemic Meis2 nulls die, but they were lethal around the time of birth. This cKO approach also allowed us to analyze older embryos. To perform lineage tracing experiments and examine migratory routes of NCC, conditional mutants AP2 $\alpha-C r e /$ Meis2 cKO were crossed to ROSA26 reporter mice [40]. This allele allows detection of Cre-mediated recombination using $\beta$-galactosidase enzymatic assay and tracing of all cells derived from AP2 $\alpha$-Cre positive NCC. Figure 5a-a' illustrates lineage tracing of $\mathrm{NCC}$ in normal and AP2 $\alpha-\mathrm{Cre} /$ Meis 2 cKO embryos. $75 \%$ of mutants ( $\mathrm{n}=8$ litters, $8 \mathrm{mu}$ tants) displayed aberrant distribution of $\beta$-galactosidasepositive cells along the neural tube (arrow in 5A'), and all mutants had abnormalities in the PA2, which appeared thinner and misshaped, (arrowheads in 5A-A') and also all mutants had smaller otic vesicles (asterisks). Sectioning of AP2 $\alpha$-Cre/Meis2 cKO/ROSA26 E10.5 embryos revealed poor colonization of the OFT by cardiac NCC (arrows in $5 B-B ')$. Conditional deletion of Meis2 effectively erased the Meis2 protein in the regions of the AP2 $\alpha$-Cre activity, however, many surrounding cells still express normal levels of Meis2 (arrows in Fig. 5c-c'). Next we studied the OFT defects at later stages using immunohistochemistry on cryosections from AP2 $\alpha$-Cre/Meis2 cKO/ROSA26 embryos. At E11, anti-Sox9 antibody labelled all $\beta$-galactosidase-positive cells in the OFT and we observed a lower density and disorganization of double-labelled cells in conditional mutants (Fig. 5d-d'). $90 \%$ of mutants had malformed OFT valves at E12 ( $\mathrm{n}=5$ litters, 9 mutants) (such as av in Fig. 5ee'). However, the septation of the truncus arteriosus appeared normal in conditional mutants as the aorta and pulmonary arteries were normally separated (Fig. $5 \mathrm{f}-\mathrm{f}^{\prime}$ ), which was never seen in systemic nulls all displaying the PTA. Of note, we detected still high levels of Meis2 in nonrecombined cells, including the smooth muscle of artery walls and in the vicinity of valves, which may provide explanation for less severe defects in conditional mutants compared to systemic ones. Finally, Fig. 5g-g' shows an example of valve malformation at E14 known as double outlet right ventricle (DORV) labelled with anti-Sox9. In summary, tissue-specific deletion of Meis 2 using AP2 $\alpha$-Cre resulted in various valve defects in the heart outflow tract documenting its critical role in cardiac NCC.

\section{Meis2 affects cranial nerve development}

As Meis2 expression is abundant in the head region, we next explored other NCC derivatives such as cranial nerves. Formation of their neuronal projections in Meis2-/- embryos was followed using whole-mount immunostaining of neurofilaments with the $2 \mathrm{H} 3$ antibody. As seen in Fig. 6a-b', the trigeminal (cranial nerve V), facial (VII) and vestibulocochlear (acoustic) nerves (VIII) were severely impaired in Meis2 nulls at E10.5 (asterisks in Fig. 6b'). An analogous analysis was performed in AP2 $\alpha$-Cre/Meis 2 cKO. We again crossed conditional mutants with ROSA26 reporters to map the activity of Cre. $\beta$-galactosidase signal in AP2 $\alpha$-Cre/ROSA26 controls was seen in trigeminal ganglions, the lens, the periocular mesenchyme and the surface ectoderm. A similar spatial pattern in this head region was found in the mutants AP2 $\alpha$-Cre/Meis2 cKO/ROSA26 and the size of the trigeminal ganglion $\mathrm{V}$ was smaller and misshapen (Fig. 6c'). 2H3 neurofilament staining showed that the cranial nerves VII and VIII were damaged in conditional mutants (asterisks in Fig. 6d') but the trigeminal nerve $\mathrm{V}$ again less affected than in Meis2-/- $(n=3$ litters, 3 mutants). Thus, the phenotype in cranial nerves appeared weaker in conditional mutants in comparison with systemic ones. We further noticed that the cornea and eyelids were not developed properly (Fig. 6e-e') (similarly in Meis2-/- embryos at E13.5, not shown). The cornea was much thinner (arrow) while eye lids (el) did not grow and close over the eye bulbs. The cornea was reported to originate from NCC [41-43] as also indicated by our lineage tracing data showing AP2 $\alpha$-Cre activity in the periocular mesenchyme (Fig. 6c). In summary, tissuespecific deletion of Meis2 in NCC and the surface ectoderm resulted in malformed cranial nerves, the cornea and eyelids.

\section{Development of cranial cartilage is perturbed in Meis2- null embryos}

Next, we examined the development of the craniofacial skeleton that is derived from NCC. Mapping of AP2 $\alpha-$ Cre/ROSA26 showed complete recombination in PA1 and otic vesicle at E10 and this was further verified at E13 on sagittal view in which recombined cells resided in jaws and the nasal cartilage (Fig. 7a). Immunostaining 


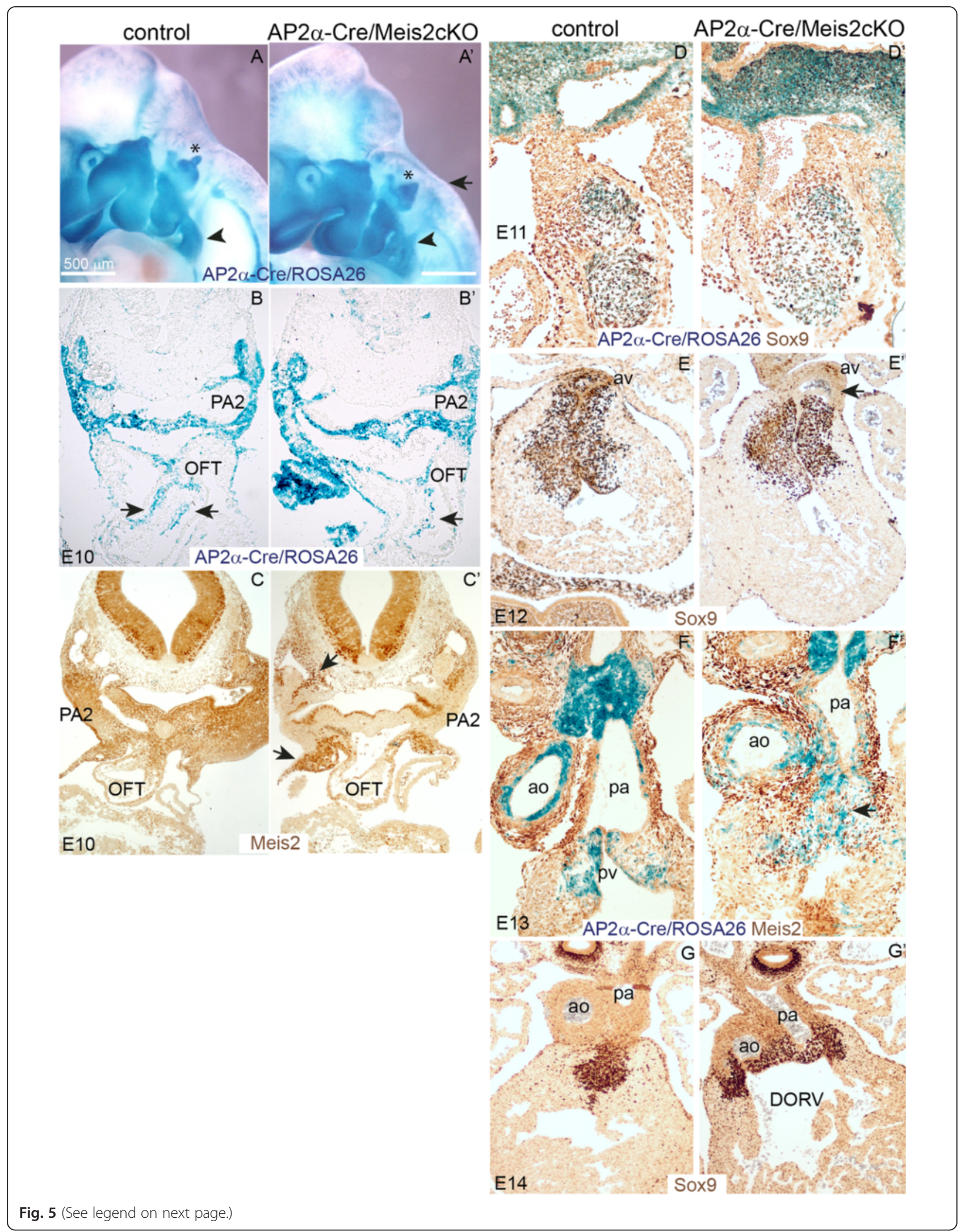


(See figure on previous page.)

Fig. 5 Heart defects upon conditional inactivation of Meis2 in NCC. (a-a') Lineage tracing of NCC in AP2a-Cre /Meis2 cKO/ROSA26 embryos at E10.5 (a') and controls (a). (b-b') Sections of embryos shown in (a) at the level of PA2 and OFT, compare position and number of $\beta$-galactosidasepositive cells in the control and the mutant cKO (arrows in $\left.\mathrm{B}^{\prime}\right)$. (c- $\left.\mathbf{c}^{\prime}\right)$ Immunohistochemical staining of Meis 2 in $\mathrm{cKO}\left(\mathbf{c}^{\prime}\right)$ shows the areas of its deletion. (d-d') Cryosetions of the OFT from AP2a-Cre /Meis2 cKO/ROSA26 stained for $\beta$-galactosidase and Sox9, note cells disorganization in cKO $\left(\mathbf{d}^{\prime}\right)$. (e-e') Paraffin-embedded sections of E12 heart stained with anti-Sox9 defective aortic valve in cKO ((e'). (f-f') Meis2 and $\beta$-galactosidase double-labeling of E13 OFT shows a number of Meis2-positive cells in CKO (f $\left.\mathbf{f}^{\prime}\right)$ that are excluded from Cre recombined areas. The pulmonary valve does not develop properly. (g-g') anti-Sox9 immunohistochemical labeling of severed valves in cKO at E14 (g'). Ao, aorta; av, aortic valve; OFT, outflow tract; PA2, pharyngeal arch 2; pa, pulmonary artery, DORV, double outlet right ventricle

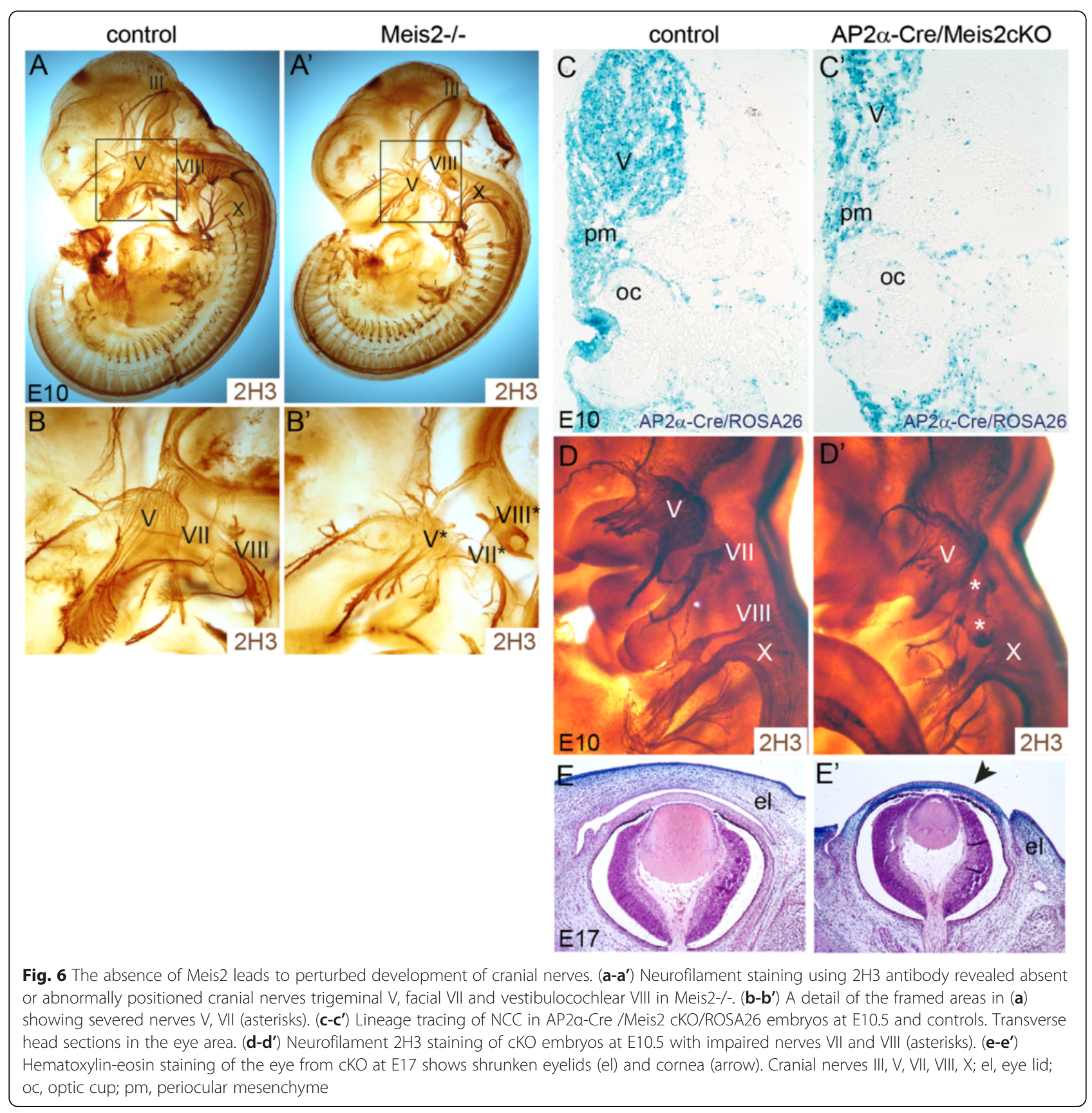




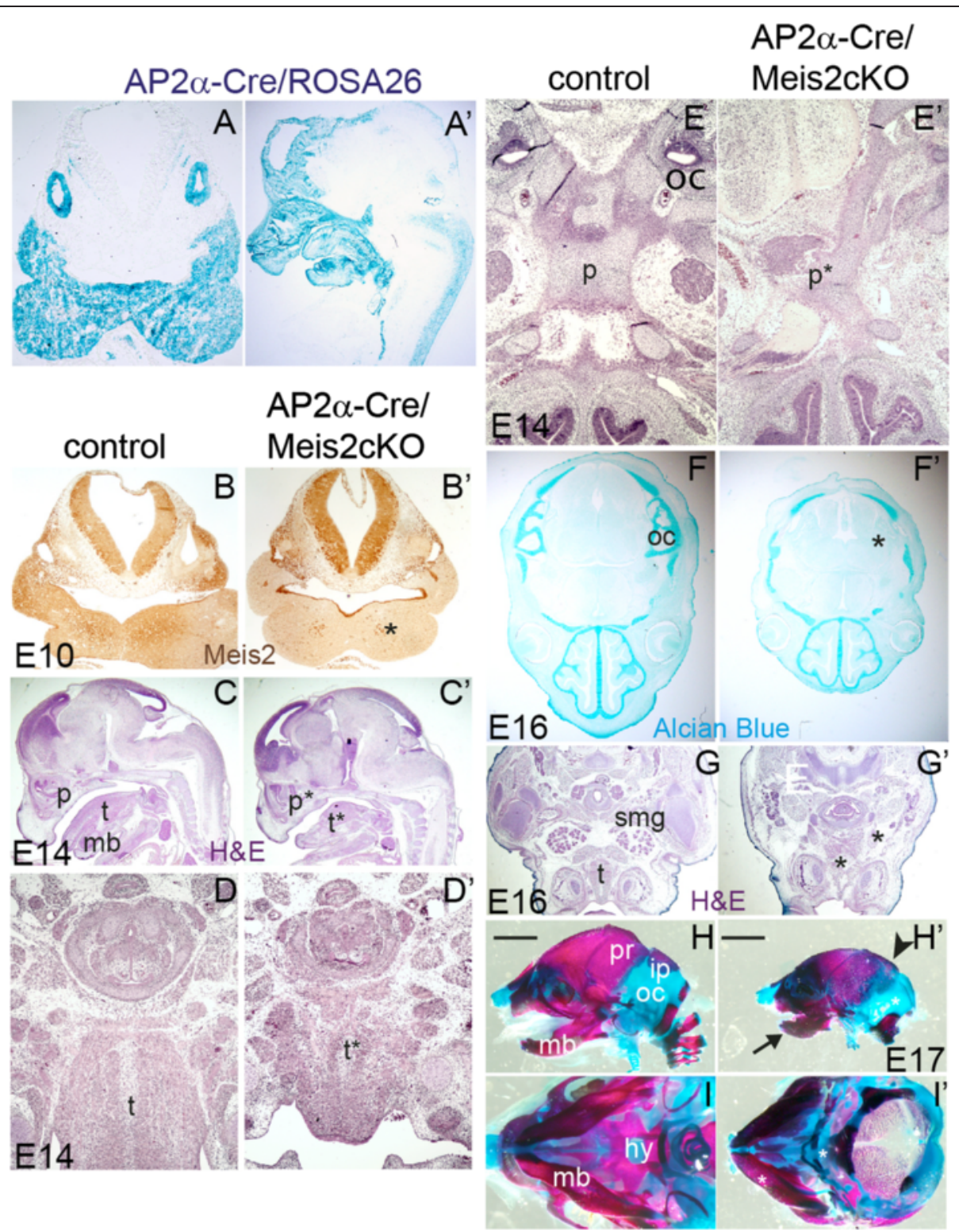

Fig. 7 Conditional inactivation of Meis2 in NCC affects osteochondrogenesis in the head. (a-a') Illustration of the zone of Cre activity visualized in AP2a-Cre/ROSA26 embryos, left: transverse section of E10.5 embryo, right: sagittal view on E13.5. (b-b) Meis2 immnunostaining of AP2a-Cre/ Meis2cKO embryos at E10.5, transverse sections in the region of hindbrain and the first pharyngeal arch. Compare the area of Meis2 deletion with a comparable cryosection from AP2a-Cre /Meis2 CKO/ROSA26 in the left panel (a). (c-c') Sagittal sections from cKO at E14, hematoxylin-eosin (H\&E) staining. Note the abnormal palate $\left(p^{*}\right)$ and tongue $\left(t^{*}\right)$. (d-d') A higher magnification of the tongue on transverse sections at E14 documents its much reduced size and tissue disorganization. (e-e') An example of severely disrupted palate ( $\left.p^{*}\right)$ in some cKO embryos, transverse section H\&E staining. Alcian staining of cartilage at E16 with no otic capsule in $\mathrm{CKO}$. (g-g') Submandibular gland is almost absent and tongue muscle severed, transverse sections. (h-h') Alizarin Red/Alcian Blue staining of E17.5 heads. Side view with remarkably shorter mandible (arrow), absent interparietal bone, abnormal hyoid bone and otic capsule cartilage. Ossification frontline of the parietal bone is severed in the mutants (arrowhead). (i-i') Ventral views showing an abnormal hyoid bone (asterisk). oc, otic capsule cartilage; ip, interparietal bone; hy, hyoid bone; mb, mandible, p, palate; pr, parietal bone; smg, submandibular gland; t, tongue

of the Meis2 protein confirmed efficient deletion in AP2 $\alpha$-Cre /Meis2 cKO in the regions of Cre recombination (asterisk in Fig. 7b', compare with the panel 7a). We found abnormal palate (p) and tongue (t) in sagittal sections of E14 conditional mutants (Fig. 7c-c'). The size of tongue was greatly reduced and muscle fibers looked disorganized, as shown in a detailed view on transverse sections (Fig. $7 d-d$ ). In $33 \%$ of mutants ( $n=6$ litters, 4 mutants), severely malformed developing cartilage were observed in the palate (asterisk in Fig. 7e'), $67 \%$ of 
mutants also displayed abnormal palates though less severe. Further, the otic capsule cartilage was absent as shown by Alcian staining at E16 (asterisk in Fig. $7 \mathrm{f}^{\prime}$ ). Submandibular gland (smg) was missing in $33 \% \mathrm{mu}-$ tants and $66 \%$ had much smaller smg (Fig. 7g-g') $(n=6$ litters, 4 and 8 mutants, respectively). We carried out whole-mount Alcian Blue/Alizarin red staining at E17.5 that confirmed our observations from tissue sections: The mandibular bone was poorly developed and its length was much shorter in the mutants (black arrow in Fig. 7h'). The interparietal bone and the cartilage of the otic capsule were absent and the boundary of ossification of the parietal bone was abnormal (arrowhead in Fig. 7h'). The hyoid bone was severely malformed (asterisk in Fig. 7i'). These defects clearly document that Meis2 is essential for the head bones and cartilages that originate from cranial NCC.

\section{Meis2 does not affect proliferation and expression of main determinants of NCC}

Migrating NCC are exposed to a number of environmental factors that can alter their properties including fate restriction or proliferation. In order to class Meis2 into the gene regulatory network determining NCC development we first examined the levels of expression of well-known genes specifying NCC. Trigeminal ganglions stained with anti-Pax3 were found reduced in size or completely missing in Meis2-/- embryos at E10 (Fig. 8a$\left.A^{\prime}\right)$. Conditional mutants showed normal levels of Pax3 and a normal size of ganglions $\mathrm{V}$ (not shown). Pax3 was reported to control colonization of the OFT by cardiac NCC [44] and the promoter of Pax3 is directly controlled by Pbx1 [45]. As Pbx1-/- embryos display similar heart defects as Meis2-/- embryos [15], we checked the expression of Pax3 in the OFT and PA2 of our mutants.

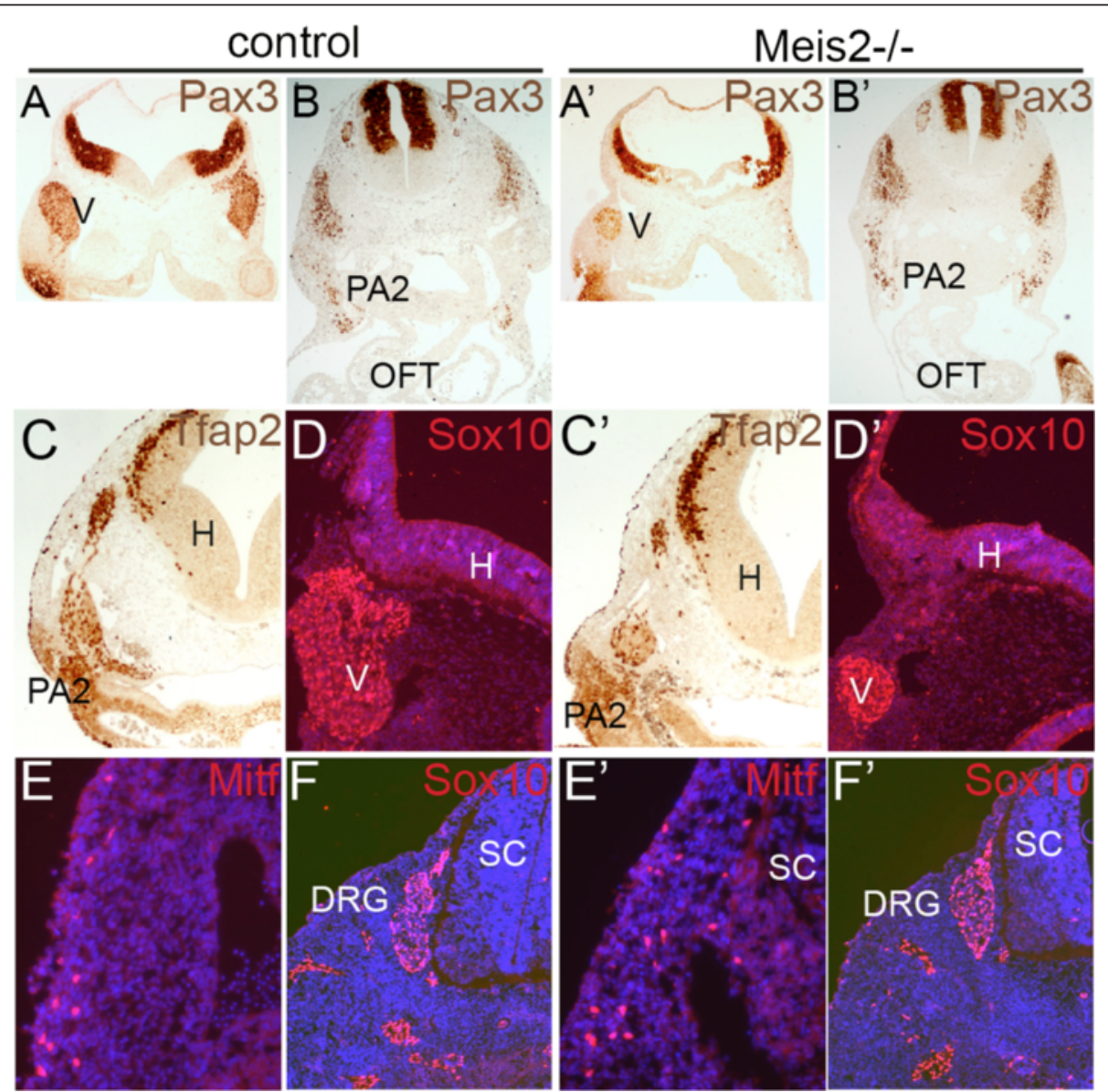

Fig. 8 Expression of NCC markers in the absence of Meis2. (a-a') Pax3 immnostaining of trigeminal ganglions in systemic Meis2-/- E10.5 embryos showing greatly reduced or even absent ganglions V. (b-b') Pax3 in the second pharyngeal arch (PA2). (c-c') Tfap2 immunostaining in Meis2-/embryos at E10.5. (d-d') Sox10 immunofluorescence of ganglions $V$ at E10.5. (e-e') Melanocytes stained with anti-Mitf were detected normally in Meis2 nulls. (f-f') Sox10 in dorsal root ganglia and the peripheral nervous system was not changed in mutants. DRG, dorsal root ganglia; $\mathrm{H}$, hindbrain; $V$, trigeminal ganglion; PA2, the second pharyngeal arch;, sc, spinal cord 
However, we found no change in Pax3-positive cells in PA2, moreover, Pax3 was not detected in the OFT even in wild-type controls (Fig. 8b-b'). Next we assayed the level of expression of Tfap2, Sox10 and Mitf, a marker of melanocyte precursors. As shown in Fig. 8c-f', their expression was not found to be changed in the absence of Meis2.

We also analyzed the number and spatial distribution of migrating NCC using anti-Sox9 antibody at E10.5. Sox9-positive NCC are abundant in the embryonic head mesenchyme and pharyngeal arches, however, their quantification did not reveal significant changes between controls and mutants (Additional file 1: Figure S4A). Further, we examined cell proliferation using antibodies against PCNA and PH3 on head sections. Again, quantification of all proliferating cells (all $\mathrm{PCNA}+$ or $\mathrm{PH} 3+$ ) or proliferating NCC (Sox9+/PCNA+) did not differ between controls and mutants (Additional file 1: Figure S4B-D). Finally, apoptosis, as measured by anti-Cas3 immunohistochemistry at E10.5, was not significantly altered in the mutants (Additional file 1: Figure S4E). In summary, Meis2 absence did not result in dramatic changes in cell proliferation and viability at E10.5.

\section{Systemic Meis2 mutants show aberrant position of FoxD3 and Sox 9}

As the defects in NCC derivatives in the absence of Meis 2 were not caused most probably by insufficient cell proliferation or changed expression of main NCC specifiers we performed whole-mount in situ hybridization to map the position of migrating NCC. At first, E9.5 embryos from Meis2-/- embryos and control littermates were stained with riboprobes for FoxD3 and Sox9 mRNA [46, 47]. As shown in Fig. 9A-B, both FoxD3 and Sox9 were expressed in Meis2-/- embryos at the levels that were comparable to control littermates, indicating again that the overall differentiation program of NCC was not affected. Interestingly, we observed an aberrant position of FoxD3-positive cranial NCC in Meis2 nulls (arrows in Fig. 9a-a'). Expression of FoxD3 mRNA in the trigeminal ganglion confirmed its abnormality as also seen in Fig. 6b'. Sox9 mRNA revealed that otic vesicles were consistently smaller in mutants (arrow in Fig. 9b'). Next, we carried out the same analysis in E9.5 embryos from conditional mutants AP2 $\alpha-C r e /$ Meis 2 cKO. However, the levels and distribution FoxD3 and Sox9 transcripts were not altered in conditional mutants ( $\mathrm{n}=5$ litters, 8 mutants) (Fig. 9c-d'). Thus, the changes in the expression pattern of NCC specifying genes Sox9 and FoxD3 were found to be more profound in systemic Meis2 mutants compared to conditional ones which may explain their stronger phenotypic defects.

\section{Discussion}

In this study, we showed that the transcription factor Meis2 is abundant in NCC and it is essential for their function. The embryonic lethal phenotypes of mutant

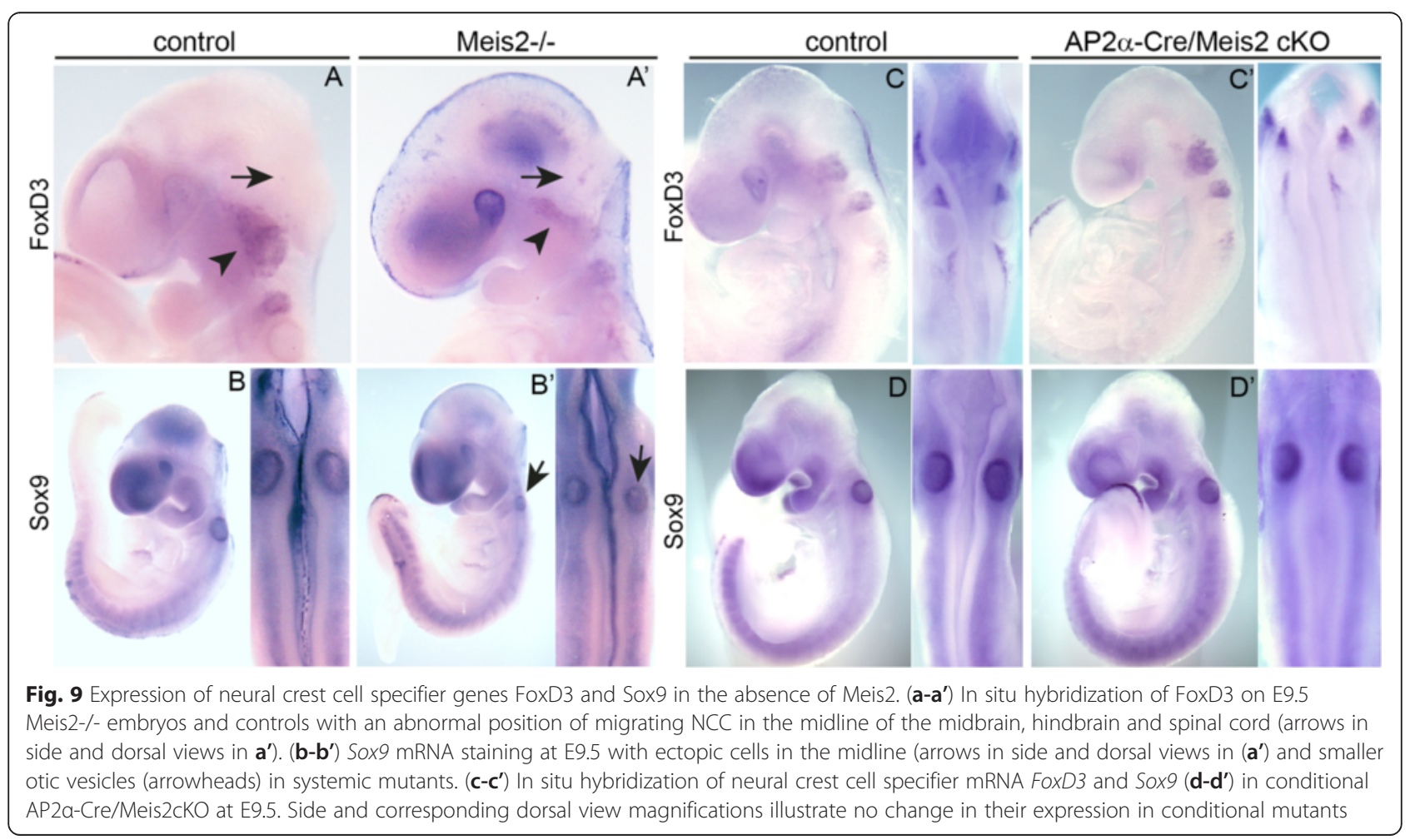


mouse embryos of Meis2 and its paralogue Meis1 are similar in the timing of death and in strong hemorrhaging. Meis1 is expressed hematopoietic stem cells in the fetal liver, the primary organ of hematopoiesis at E13. Various assays showed defects in erythropoiesis providing explanation for anemia in Meis1 mutants [25, 26]. In contrast, we did not detect Meis2 in the fetal liver and in hematopoietic progenitors in the dorsal aorta. We therefore speculate that hemorrhaging in Meis2-/- embryos caused destructive changes primarily in the fetal liver that is highly sensitive to low oxygen. Impaired function of the liver may lead to failure in erythropoiesis and thus bleeding rather than defects in hematopoiesis in Meis2 mutants may cause lethality. Despite $83 \%$ sequence identity of Meis1 and Meis2 and the almost identical homeodomain, they acquired different functions during evolution probably due to distinct expression patterns.

Stankunas and colleagues $[15,45]$ showed that various combinations of mutant alleles of $\mathrm{Pbx} 1 / 2 / 3$ or Meis 1 exhibit cardiac anomalies in the outflow tract or in the septation of ventricles implying that cardiac NCC require transcriptional control by combinatory Meis/Pbx complexes. Along this line, zebrafish Meis2 genes influence development of heart and cranial skeleton $[16,28]$. The data presented here extend our knowledge about the role of Meis/Pbx complexes controling the fate of NCC. Apart from the previously proposed function in cardiac neural crest, we suggest that a similar transcriptional control network takes place in cranial NCC including chondrogenic and neuronal lineages. Our data represent the first loss-of-function study of Meis2 in mouse and may in fact serve as a disease model for certain human developmental disorders. Intriguingly, several reports describe patients with Meis2 mutations who display disorders such as the cleft palate, septal defects in the heart or intellectual disabilities [30-33].

Pax3 is expressed in the neural plate border and plays an important role in cardiac NCC as documented by conditional knock-out studies in mouse [44]. A specific $\mathrm{Pbx} 1 /$ Meis1 complex has been reported to directly regulate Pax3 in premigratory NCC in rhombomeres, in which cardiac NCC originate, linking Pbx1-Pax3 regulatory hierarchy with the OFT defects in Pbx1-/- embryos [45]. We did not see reduced Pax3 expression in Meis2-/- at E10.5 although Pax3-positive trigeminal ganglions were shrunken in systemic mutants. Nor could we detect Pax3 in the wild-type OFT at E10.5. It is possible that Meis2 and Pax3 are co-expressed in earlier NCC in which these factors may cooperate during NCC differentiation.

Our experiments utilizing conditional mutants AP2 $\alpha$ Cre/Meis 2 cKO confirm defects in tissues derived from cardiac and cranial NCC such as the OFT or craniofacial cartilage. However, the phenotypes in cKO appeared in some cases weaker than in systemic mutants. PTA, for instance, was never found in conditional mutants while all systemic mutants displayed defective septation of the OFT. It is important to note that we still found a substantial amount of Meis2 protein after conditional deletion in the areas that are in close vicinity of AP2 $\alpha$-Cre targeted regions (mapped in the ROSA26 reporter) in which we observed effective inactivation. Standby Meis2-positive cells may be involved in forming the truncus septum. Although AP $2 \alpha$-Cre mouse is the earliest driver for NCC [44], we cannot exclude the possibility that a minor NCC population forms before AP2 $\alpha$ Cre mediated recombination and thus it is not targeted. Another possibility is that neighboring non-NCC cells expressing Meis2 participate in the truncus septation. In this context it is interesting to note that systemic Pax3 KO display the PTA while Wnt1-Cre or AP2 $\alpha-C r e$ cKOs of Pax3 show valve defects but normal separation of aorta and pulmonary arteries [44]. Moreover, the PTA defects were also seen in systemic Pbx1-3 mutants; the data from Pbx cKOs are not available [15, 45]. The fact that the truncus septation may partially originate from non-NCC population is supported by the report of Bai and colleagues [48] who observed PTA in Mef2c-Cre/ Bmp4/7, a Cre driver not normally used for NCC targeting.

Altered proliferation, apoptosis or significant changes in expression of transcription factors determining NCC (Sox9, Sox10, Tfap2, Pax3, Mitf) were not detected between critical stages E10.5-E11.5 in our hands. Meis2 may influence late phases of NCC differentiation (including cell proliferation and viability) that is required for proper formation of the OFT or for differentiation of osteochondral progenitors.

We hypothesize that Meis2 absence may be compensated by Meis1 which may rescue some defects during earlier phases of NCC development. Meis2 deficiency is thus reflected in the areas and stages in which the Meis2 function is unique, e.g. during craniofacial development. Meis proteins may diversify in their expression pattern after the initial NCC specification and acquire unique function, for instance, during formation of the OFT and cartilage. In order to test this hypothesis it will be necessary to generate and analyze Meis1 and Meis2 conditional double mutants that may reveal potentially earlier role of Meis factors during NCC development.

Even though we did not see a major difference in Sox9 expression in early embryos, anomalies in the craniofacial skeleton of Wnt1-Cre/Sox9 cKO [47] and our AP2 $\alpha$-Cre/Meis2 cKO are similar in the mandible, tongue, the otic capsule and the hyoid bone. This suggests that Sox9 and Meis2 cooperate in a similar differentiation process during chondrogenesis. It remains to 
be elucidated what genes are direct targets of Meis factors. Altogether, our loss-of-function studies show that Meis2 transcription is an important player in the gene regulatory network determining differentiation of cardiac and cranial NCC.

\section{Methods}

\section{Generation of Meis2 null mice}

The LoxP recognition elements for the Cre recombinase were inserted in the introns 2 and 6 of the Meis 2 gene at the Gene Targeting \& Transgenic Facility, University of Connecticut, USA. Transgenic mice termed Meis2 cKO were created by standard techniques using homologous recombination in mouse embryonic stem cells $(129 \mathrm{SvEv}-$ Tac/C57BL/6 J F1) also at the Gene Targeting \& Transgenic Facility. A neomycin selection cassette was removed using FLP-FRT recombination. Meis2 cKO were crossed to Hprt-Cre mice (strain 129S1/Sv-Hprt ${ }^{\mathrm{tm} 1(\mathrm{cre}) \mathrm{Mnn}} / \mathrm{J}$, stock 004302, The Jackson Laboratory) with the zygotic activity of the Cre recombinase to obtain animals that were heterozygous for Meis2 (Meis2+/-) in the mixed genetic background. Primers for genotyping Meis2+/- alleles: Mrg1-lox-F (forward) GAGGGGACAGTGGGTAAACA, Mrg1-frt-R (reverse) TCAGACCCAGGAATTTGAGG, a PCR product of $256 \mathrm{bp}$. Wild-type allele: Mrg1-frt-F GCAAGGGTGCTGAGGTTAAA and Mrg1-frt-R TCA GACCCAGGAATTTGAGG, a PCR product 235 bp. (Fig. 1a). Alternatively, Mrg1-lox-F GAGGGGACAGTG GGTAAACA, Mrg1-lox-R GCGTTGCAGCTCACAAGA AT, a PCR product of $142 \mathrm{bp}$.

All procedures involving experimental animals were approved by the Institutional Committee for Animal Care and Use (permission \#PP-071/2011). This work did not include human subjects.

\section{Immunohistochemistry}

Embryos were fixed in $4 \%$ paraformaldehyde overnight at $4{ }^{\circ} \mathrm{C}$. $8-10 \mu \mathrm{m}$ cryosections or 5- $\mu \mathrm{m}$ (paraffin-embedded) sections were permeabilized in $0.1 \%$ Triton X-100 in PBS (PBT). After blocking sections were incubated overnight in a primary antibody (1\% BSA in PBT), washed with PBS and incubated with a fluorescent secondary for $1 \mathrm{~h}$. Nuclei were visualized by DAPI (4,6-diamidino-2-phenylindol, $0.1 \mu \mathrm{g} \mathrm{ml}{ }^{-1}$, Roche). Primary antibodies: anti-Meis2 and anti-Meis1 (a gift from Dr. Buchberg), anti-Myl7 (1:250, Santa Cruz), smooth muscle actin (SMA) (1:1000, Sigma), Sox10, Twist1 (all Santa Cruz Biotech), 2H3 (neurofilaments), 3B5 (Tfap2a) and Pax3 (all DSHB), anti-alpha sarcomeric actin clone $5 \mathrm{C} 5$, anti-alpha smooth muscle actin clone 1A4 (both Sigma), anti-Myl7 (H60) (Santa Cruz Biotech), Mitf (a gift from Dr. H. Arnheiter), anti-Ter119 (BD Pharmingen). Secondary antibodies: anti-mouse (-rat, -rabbit) Alexa Fluor488 or 594 (Life Technologies). Biotinylated- anti-mouse, -anti-rabbit, -anti-rat (Vector Laboratories), Vectastain ABC Elite kit and ImmPACT DAB substrate (all Vector Laboratories). Images were acquired in Leica MZ APO stereomicroscope with DC200 camera or Olympus SZX9 with DP72 camera. Fluorescence images were acquired in Zeiss Axioskop 2 microscope with objectives Ph3 Plan-Neofluar 40x/1.3 oil or Ph1 PlanNeofluar 10x/0.3 and confocal Leica SP5. Bright-field light images were acquired in Nikon Diaphot 300 with objectives $4 x / 0.1$ and $10 x / 0.25$.

\section{Scale2 protocol}

Dissected embryonic hearts were fixed overnight in $4 \%$ PFA, washed in PBS and transferred into ScaleA2 reagent (4 M urea, $10 \%$ glycerol, $0.1 \%$ triton X-100) as described in [49]. After two hours at RT hearts were photographed.

\section{Alcian blue/Alizarin red staining}

Embryos at E16.5-17.5 were dissected and scalded in hot water $\left(65-70{ }^{\circ} \mathrm{C}, 2 \mathrm{~min}\right)$. They were dehydrated in $95 \%$ ethanol for 48-72 h, changing solution every $12 \mathrm{~h}$. After Alcian blue (Sigma) staining for $12 \mathrm{~h}$, they were rinsed twice in ethanol and kept overnight. After clearing in $1 \% \mathrm{KOH}$ for $2 \mathrm{~h}$ and they were stained with Alizarin red (Sigma) for $5 \mathrm{~h}$. Further clearing in $2 \% \mathrm{KOH}$ was carried out overnight, then in Glycerol (25\%) and $2 \%$ $\mathrm{KOH}(75 \%)$ for $8 \mathrm{~h}$ and Glycerol (50 \%) and $2 \% \mathrm{KOH}$ (50 \%) for $48 \mathrm{~h}$. Tissue sections were rehydrydated and stained in $0.04 \%$ Alcian solution for $10 \mathrm{~min}$. Pictures were obtained using binocular microscope Olympus SYX9 and camera Olympus DP72.

\section{Whole-mount in situ hybridization}

Riboprobes: Mouse Foxd3 was cloned into pGEM-Teasy vector (Promega) using primers F-GGACCGCAA GAGTTCGCGGA, R-TCCGGAGCTCCCGTGTCGTT and antisense mRNA was transcribed with T7 polymerase. Mouse Sox 9 gene was cloned into pGEM-T-easy using primers F-GAGCACTCTGGGCAATCTCAG, RCTCAGGGTCTGGTGAGCTGTG and antisense mRNA was transcribed with T7 polymerase. Whole-mount in situ hybridization was performed using standard protocols.

\section{Conclusions}

We present a pioneering functional description of Meis2, a member of TALE-class homeodomain transcription factors, which is strongly expressed in cranial neural crest cells. We generated a conditional allele of the Meis2 gene. Using systemic and neural crest-specific inactivation of Meis2, we provide evidence that Meis2 is an important player in the regulatory network controlling cranial and cardiac neural crest cells. 


\section{Additional file}

Additional file 1: Figures S1-S4. Fetal liver in Meis2-/- at E13.5 contains less erythrocytes and loses cell viability. Figure S2. Meis2 is abundant in the mesenchyme of the aorta-gonadmesonephros (AGM). Figure S3. Meis2 is strongly expressed in migrating NCC and in mesenchymal cells at E10.5. Figure S4. Proliferation and cell death of migrating NCC appears normal in Meis2-/- mutants. (PDF 1406 kb)

\section{Abbreviations}

ao: aorta; CKO: conditional knock-out; DORV: double outlet right ventricle; MO: morpholino; NCC: neural crest cells; OFT: outflow tract; pa: Pulmonary artery; PTA: persistent truncus arteriosus; EMT: epithelial-mesenchymal transtition.

\section{Competing interests}

The authors declare no competing financial and non-financial interests.

\section{Authors' contributions}

OM designed and performed experiments, interpreted data and wrote the manuscript. JM commented on the manuscript and performed experiments. OM performed experiments. SK, ZK interpreted data and commented on the manuscript. All authors have read and approved the manuscript.

\section{Acknowledgments}

The work was supported by the Norwegian Research Council (grant \#174938) (OM, SK) and the Grant Agency of the Czech Republic (P305/12/ 2042) (OM, JM) and LK11214 (OM, JM) from the Ministry of Education, Youth and Sports of the Czech Republic. We are grateful to A. Buchberg (Thomas Jefferson University, Philadelphia, USA) for anti-Meis2.

\section{Author details}

${ }^{1}$ Institute of Molecular Genetics, The Czech Academy of Sciences, 14200 Praha, Czech Republic. ${ }^{2}$ Unit for Cell Signaling, Oslo University Hospital, N-0349 Oslo, Norway.

Received: 11 August 2015 Accepted: 3 November 2015 Published online: 06 November 2015

\section{References}

1. Bronner ME, LeDouarin NM. Development and evolution of the neural crest: an overview. Dev Biol. 2012;366(1):2-9.

2. Dupin E, Sommer L. Neural crest progenitors and stem cells: from early development to adulthood. Dev Biol. 2012;366(1):83-95.

3. Sauka-Spengler T, Bronner-Fraser M. A gene regulatory network orchestrates neural crest formation. Nat Rev Mol Cell Biol. 2008;9(7):557-68.

4. Stuhlmiller TJ, Garcia-Castro MI. Current perspectives of the signaling pathways directing neural crest induction. Cell Mol Life Sci. 2012;69(22):3715-37.

5. Minoux M, Rijli FM. Molecular mechanisms of cranial neural crest cell migration and patterning in craniofacial development. Development. 2010;137(16):2605-21.

6. Santagati F, Rijli FM. Cranial neural crest and the building of the vertebrate head. Nat Rev Neurosci. 2003;4(10):806-18.

7. Kirby ML, Hutson MR. Factors controlling cardiac neural crest cell migration. Cell Adh Migr. 2010;4(4):609-21.

8. Lee RT, Nagai H, Nakaya Y, Sheng G, Trainor PA, Weston JA, et al. Cell delamination in the mesencephalic neural fold and its implication for the origin of ectomesenchyme. Development. 2013;140(24):4890-902.

9. Nakamura $T$, Jenkins NA, Copeland NG. Identification of a new family of Pbx-related homeobox genes. Oncogene. 1996;13(10):2235-42.

10. Jacobs Y, Schnabel CA, Cleary ML. Trimeric association of Hox and TALE homeodomain proteins mediates Hoxb2 hindbrain enhancer activity. Mol Cell Biol. 1999;19(7):5134-42.

11. Shanmugam K, Green NC, Rambaldi I, Saragovi HU, Featherstone MS. PBX and MEIS as non-DNA-binding partners in trimeric complexes with HOX proteins. Mol Cell Biol. 1999;19(11):7577-88.

12. Knoepfler PS, Bergstrom DA, Uetsuki T, Dac-Korytko I, Sun YH, Wright WE, et al. A conserved motif $\mathrm{N}$-terminal to the DNA-binding domains of myogenic bHLH transcription factors mediates cooperative DNA binding with pbx-Meis1/Prep1. Nucleic Acids Res. 1999;27(18):3752-61.

13. Mercader N, Leonardo E, Azpiazu N, Serrano A, Morata G, Martinez C, et al. Conserved regulation of proximodistal limb axis development by Meis $1 / \mathrm{Hth}$. Nature. 1999;402(6760):425-29.

14. Capdevila J, Tsukui T, Rodriquez EC, Zappavigna V, Izpisua Belmonte JC. Control of vertebrate limb outgrowth by the proximal factor Meis2 and distal antagonism of BMPs by Gremlin. Mol Cell. 1999;4(5):839-49.

15. Stankunas K, Shang C, Twu KY, Kao SC, Jenkins NA, Copeland NG, et al. Pbx/ Meis deficiencies demonstrate multigenetic origins of congenital heart disease. Circ Res. 2008;103(7):702-09.

16. Paige $S L$, Thomas $S$, Stoick-Cooper $C L$, Wang $H$, Maves $L$, Sandstrom $R$, et al. A temporal chromatin signature in human embryonic stem cells identifies regulators of cardiac development. Cell. 2012;151(1):221-32.

17. Zhang X, Friedman A, Heaney S, Purcell P, Maas RL. Meis homeoproteins directly regulate Pax6 during vertebrate lens morphogenesis. Genes Dev. 2002;16(16):2097-107.

18. Zhang X, Rowan S, Yue Y, Heaney S, Pan Y, Brendolan A, et al. Pax6 is regulated by Meis and $\mathrm{Pbx}$ homeoproteins during pancreatic development. Dev Biol. 2006;300(2):748-57.

19. Choe SK, Vlachakis N, Sagerstrom CG. Meis family proteins are required for hindbrain development in the zebrafish. Development. 2002;129(3):585-95.

20. Vlachakis N, Choe SK, Sagerstrom CG. Meis3 synergizes with Pbx4 and Hoxb1b in promoting hindbrain fates in the zebrafish. Development. 2001;128(8):1299-312.

21. Waskiewicz AJ, Rikhof HA, Hernandez RE, Moens CB. Zebrafish Meis functions to stabilize Pbx proteins and regulate hindbrain patterning Development. 2001;128(21):4139-51.

22. Agoston Z, Schulte D. Meis2 competes with the Groucho co-repressor Tle4 for binding to Otx2 and specifies tectal fate without induction of a secondary midbrain-hindbrain boundary organizer. Development. 2009;136(19):3311-22.

23. Choe SK, Lu P, Nakamura M, Lee J, Sagerstrom CG. Meis cofactors contro HDAC and CBP accessibility at Hox-regulated promoters during zebrafish embryogenesis. Dev Cell. 2009;17(4):561-67.

24. Ladam F, Sagerstrom CG. Hox regulation of transcription: more complex(es). Dev Dyn. 2014:243(1):4-15.

25. Azcoitia V, Aracil M, Martinez A, Torres M. The homeodomain protein Meis1 is essential for definitive hematopoiesis and vascular patterning in the mouse embryo. Dev Biol. 2005;280(2):307-20.

26. Hisa T, Spence SE, Rachel RA, Fujita M, Nakamura T, Ward JM, et al. Hematopoietic, angiogenic and eye defects in Meis1 mutant animals. EMBO J. 2004;23(2):450-59.

27. Heine P, Dohle E, Bumsted-O'Brien K, Engelkamp D, Schulte D. Evidence for an evolutionary conserved role of homothorax/Meis $1 / 2$ during vertebrate retina development. Development. 2008;135(5):805-11.

28. Melvin VS, Feng W, Hernandez-Lagunas L, Artinger KB, Williams T. A morpholino-based screen to identify novel genes involved in craniofacial morphogenesis. Dev Dyn. 2013;242(7):817-31.

29. DeLaughter DM, Christodoulou DC, Robinson JY, Seidman CE, Baldwin HS, Seidman JG, et al. Spatial transcriptional profile of the chick and mouse endocardial cushions identify novel regulators of endocardial EMT in vitro. J Mol Cell Cardiol. 2013;59:196-204.

30. Erdogan F, Ullmann R, Chen W, Schubert M, Adolph S, Hultschig C, et al. Characterization of a $5.3 \mathrm{Mb}$ deletion in $15 \mathrm{q} 14$ by comparative genomic hybridization using a whole genome "tiling path" BAC array in a girl with heart defect, cleft palate, and developmental delay. Am J Med Genet A. 2007;143(2):172-78.

31. Johansson S, Berland S, Gradek GA, Bongers E, de LN, Pfundt R, et al. Haploinsufficiency of MEIS2 is associated with orofacial clefting and learning disability. Am J Med Genet A. 2014;164A(7):1622-6.

32. Crowley MA, Conlin LK, Zackai EH, Deardorff MA, Thiel BD, Spinner NB. Further evidence for the possible role of MEIS2 in the development of cleft palate and cardiac septum. Am J Med Genet A. 2010;152A(5):1326-27.

33. Louw JJ, Corveleyn A, Jia Y, Hens G, Gewillig M, Devriendt K. MEIS2 involvement in cardiac development, cleft palate, and intellectual disability. Am J Med Genet A. 2015;167A(5):1142-6.

34. Cai M, Langer EM, Gill JG, Satpathy AT, Albring JC, KC W, et al. Dual actions of Meis1 inhibit erythroid progenitor development and sustain general hematopoietic cell proliferation. Blood. 2012;120(2):335-46. 
35. Rinon A, Lazar S, Marshall H, Buchmann-Moller S, Neufeld A, Elhanany-Tamir $\mathrm{H}$, et al. Cranial neural crest cells regulate head muscle patterning and differentiation during vertebrate embryogenesis. Development. 2007;134(17):3065-75.

36. Schorle H, Meier P, Buchert M, Jaenisch R, Mitchell PJ. Transcription factor AP-2 essential for cranial closure and craniofacial development. Nature. 1996:381(6579):235-38.

37. Zhang J, Hagopian-Donaldson S, Serbedzija G, Elsemore J, Plehn-Dujowich D, McMahon AP, et al. Neural tube, skeletal and body wall defects in mice lacking transcription factor AP-2. Nature. 1996;381(6579):238-41.

38. Cecconi F, Proetzel G, varez-Bolado G, Jay D, Gruss P. Expression of Meis2, a Knotted-related murine homeobox gene, indicates a role in the differentiation of the forebrain and the somitic mesoderm. Dev Dyn. 1997;210(2):184-90.

39. Macatee TL, Hammond BP, Arenkiel BR, Francis L, Frank DU, Moon AM Ablation of specific expression domains reveals discrete functions of ectoderm- and endoderm-derived FGF8 during cardiovascular and pharyngeal development. Development. 2003;130(25):6361-74.

40. Soriano P. Generalized lacZ expression with the ROSA26 Cre reporter strain. Nat Genet. 1999;21(1):70-1.

41. Hatou S, Yoshida S, Higa K, Miyashita H, Inagaki E, Okano H, et al. Functional corneal endothelium derived from corneal stroma stem cells of neural crest origin by retinoic acid and Wnt/beta-catenin signaling. Stem Cells Dev. 2013;22(5):828-39.

42. Yoshida S, Shimmura S, Nagoshi N, Fukuda K, Matsuzaki Y, Okano H, et al. Isolation of multipotent neural crest-derived stem cells from the adult mouse cornea. Stem Cells. 2006;24(12):2714-22.

43. Ittner LM, Wurdak H, Schwerdtfeger K, Kunz T, Ille F, Leveen P, et al. Compound developmental eye disorders following inactivation of TGFbeta signaling in neural-crest stem cells. J Biol. 2005;4(3):11.

44. Olaopa M, Zhou HM, Snider P, Wang J, Schwartz RJ, Moon AM, et al. Pax3 is essential for normal cardiac neural crest morphogenesis but is not required during migration nor outflow tract septation. Dev Biol. 2011;356(2):308-22.

45. Chang CP, Stankunas K, Shang C, Kao SC, Twu KY, Cleary ML. Pbx 1 functions in distinct regulatory networks to pattern the great arteries and cardiac outflow tract. Development. 2008;135(21):3577-86.

46. Mundell NA, Labosky PA. Neural crest stem cell multipotency requires Foxd3 to maintain neural potential and repress mesenchymal fates. Development. 2011;138(4):641-52.

47. Mori-Akiyama Y, Akiyama H, Rowitch DH, de CB. Sox9 is required for determination of the chondrogenic cell lineage in the cranial neural crest. Proc Natl Acad Sci U S A. 2003;100(16):9360-65.

48. Bai Y, Wang J, Morikawa Y, Bonilla-Claudio M, Klysik E, Martin JF. Bmp signaling represses Vegfa to promote outflow tract cushion development. Development. 2013;140(16):3395-402.

49. Hama H, Kurokawa $H$, Kawano $H$, Ando R, Shimogori T, Noda H, et al. Scale: a chemical approach for fluorescence imaging and reconstruction of transparent mouse brain. Nat Neurosci. 2011;14(11):1481-88.

\section{Submit your next manuscript to BioMed Central and take full advantage of:}

- Convenient online submission

- Thorough peer review

- No space constraints or color figure charges

- Immediate publication on acceptance

- Inclusion in PubMed, CAS, Scopus and Google Scholar

- Research which is freely available for redistribution

Submit your manuscript at www.biomedcentral.com/submit 